\title{
An anomalous atmospheric river linked to the late June 2021 western North America heatwave
}

\section{Ruping Mo ( $\nabla$ ruping.mo@ec.gc.ca )}

Environment and Climate Change Canada https://orcid.org/0000-0002-0284-0439

\section{Hai Lin}

Environment Canada

\section{Frédéric Vitart}

European Centre for Medium-Range Weather Forecasts

\section{Article}

Keywords: Atmospheric rivers (ARs), atmospheric river (AR), integrated water vapour (IWV), integrated vapour transport (IVT)

Posted Date: January 6th, 2022

DOI: https://doi.org/10.21203/rs.3.rs-1125330/v1

License: (9) This work is licensed under a Creative Commons Attribution 4.0 International License. Read Full License

Version of Record: A version of this preprint was published at Communications Earth \&amp; Environment on June 2nd, 2022. See the published version at https://doi.org/10.1038/s43247-022-00459-w. 
1 An anomalous atmospheric river linked to the late June 2021

2 western North America heatwave

3 Ruping $\mathrm{Mo}^{1, *}$, Hai $\operatorname{Lin}^{2}$ and Frédéric Vitart ${ }^{3}$

$4 \quad{ }^{1}$ Environment and Climate Change Canada, Vancouver, Canada

$5 \quad{ }^{2}$ Environment and Climate Change Canada, Montreal, Canada

$6 \quad{ }^{3} E C M W F$, Reading, $U K$

$7 \quad{ }^{*}$ Correspondence: ruping.mo@ec.gc.ca

8 Atmospheric rivers (ARs) are long and narrow bands of enhanced water vapour flux

9 concentrate $d$ in the lower tropos phere. Many studies have documented the important role

10 of cold-s eas on ARs in producing he avy pre cipitation and trigge ring extre me flooding in

11 many parts of the world. However, relatively little research has been conducted on the

12 warm-se ason ARs and their impacts on extre me heatwave development. Here we show an

13 anomalous warm-seas on AR moving across the North Pacific and its interaction with the

14 western North American he atwave in late June 2021. We call it an "oriental express" to

15 highlight its capability to transport tropical mois ture to the west coast of North America

16 from sources in Southeast Asia. Its landfall over the Alaska Panhandle lasted for more than

17 two days and resulted in significant spillover of moisture into western Canada. We provide

18 evidence that the injected water vapour was trapped under the he at dome and may have

19 formed a positive feedback mechanis $m$ to regulate the heatwave development in western

20 North America.

The concept of the atmospheric river (AR) as a filamentary structure in atmospheric water

22 vapour transport has been around since the $1990 \mathrm{~s}^{1-3}$, and can even be dated back to the

23 conceptual models of "warm conveyor belt" in the $1970 \mathrm{~s}^{4-6}$ and "moist tongue" in the 1930s 
24 ARs are typically associated with a low-level jet stream ahead of the cold front of an

25 extratropical cyclone, and frequently lead to heavy precipitation when they are forced upward by

26 mountains or frontal forcing8,9. Along the west coast of North America (NA), high-impact ARs

27 often arrive in the cold season when weather is dominated by the strong onshore flow of Pacific

28 airstreams. Some of these ARs are also known as "pineapple express" storms for their apparent

29 origin in the tropical area near Hawaii ${ }^{10-13}$. Their landfall on mountainous areas can produce

30 extremely heavy precipitation events and may trigger hazardous floods, mudslides, and

31 avalanches. Intense ARs are rare over the northeast Pacific in the warm season, when a ridge of

32 high pressure tends to lie off the west coast of NA. Here we investigate an anomalous summer

33 AR which moved across the North Pacific and made a prolonged landfall over the Alaska

34 Panhandle during June 24-26, 2021. Our analysis indicates that this AR was capable of

35 transporting tropical warm moist air from Southeast Asia into the NA continent. We have called

36 it an "oriental express" to emphasize this unique connection. The track for this express was

37 controlled mainly by an unseasonably deep Aleutian Low in conjunction with a stable North

38 Pacific High. A trans-Pacific wave train was also identified in the mid-troposphere. Its

39 connection with the boreal summer intraseasonal oscillation in Southeast Asia ${ }^{14}$ and the western

40 NA heatwave have been examined in a separate study ${ }^{15}$. In this article, we provide an in-depth

41 analysis of the hydrometeorological impacts of the AR in NA. It is shown that the 3-day landfall

42 of the AR produced only moderate to locally heavy precipitation over the Alaska Panhandle. The

43 more important effect was its inland-penetration across the Pacific Coast Ranges which

44 transported moisture into western Canada. Given that water vapour is the dominant greenhouse

45 gas in the atmosphere ${ }^{16-20}$, we establish a possible link between the moisture trapped under the

46 ridge of high pressure and the heat wave development in western NA. Correlation analysis shows

47 that the 5-day (26-30 June) mean air temperatures are positively correlated with the mean water

48 vapour content across Canada. Although the cause of these positive correlations may be

49 attributed mainly to the fact that as temperatures rise, more water vapour can be present in the

50 atmosphere before saturation occurs, there is evidence for a positive moisture feedback through 
51 the greenhouse effect that contributed to the heatwave intensification in western Canada in late

52 June 2021. Our verification analysis also shows that when a numerical weather prediction

53 (NWP) model failed to predict the inland penetration of the AR, it also failed to predict the

54 severity of the following heatwave in western Canada.

\section{Oriental express: a trans-Pacific AR with its origin in Southeast Asia}

ARs are often defined based on the vertically integrated vapour transport (IVT) derived

57 from specific humidity and wind profiles (Methods) ${ }^{1-3,21-23}$. Based on the ERA5 global reanalysis ${ }^{24}$, the IVT distributions over the North Pacific basin valid at 0000 UTC June 21-26, 2021 are shown in Fig. 1. The corresponding distributions of sea level pressure (SLP), 500-hPa geopotential height (Z500), and integrated water vapour (IWV) are shown in Figures S1-S3 in the supplementary information (SI). Here one can apply either the $\mathrm{IVT}_{250}$ or the $\mathrm{IVT}_{500} \mathrm{scheme}$ outlined in the Methods section for AR identification. Figure 1 characterises the northeastward advance of a substantial AR across the North Pacific basin. In general, this AR was driven mainly by a twin-engine system consisting of the anomalously deep Aleutian Low and the stable subtropical North Pacific High. It was linked to the Asian summer monsoon system through most of its lifespan. This connection is the inspiration for calling it the oriental express, analogous to the pineapple express that brings warm and moist air from tropical sources near

68 Hawaii to the west coast of NA.

Two ARs can be identified in the North Pacific at 0000 UTC June 21, 2021 (Fig. 1a). The one in the east was driven by a cyclone in the Gulf of Alaska $\left(\mathrm{L}_{1003}\right)$ with a strong anticyclone to its south $\left(\mathrm{H}_{1029}\right)$. It made landfall on the Alaska Panhandle about 12 hours earlier and was rapidly dissipating. The major AR was the oriental express driven by the Aleutian Low (L 979$)$ into the northeast Pacific from the west. The minimum SLP at the cyclonic centre was $979 \mathrm{hPa}$,

74 which was $31 \mathrm{hPa}$ below the climatological mean value of $1010 \mathrm{hPa}$ at that location (Fig. 2a). On

75 the northern flank of this AR there were also two secondary cyclones $\left(\mathrm{L}_{1001}\right.$ and $\left.\mathrm{L}_{995}\right)$ centred at 
$76\left(28^{\circ} \mathrm{N}, 125^{\circ} \mathrm{E}\right)$ and $\left(39^{\circ} \mathrm{N}, 148^{\circ} \mathrm{E}\right)$, respectively. They were locally interacting with the AR and

77 helped pump moisture from the South China Sea into the AR system. The North Pacific High

78 spawned a secondary centre west of the 180th meridian $\left(\mathrm{H}_{1021}\right)$. Anticyclonic flow around this

79 western centre transported warm moist air from the tropical western Pacific into the AR system.

80 These features were maintained through the following two days as the Aleutian Low moved

81 eastward across the 180th meridian and gradually weakened (Fig. 1b,c).

The Aleutian Low re-strengthened rapidly through June 23rd with the minimum SLP

83 falling to $973 \mathrm{hPa}$ around 0000 UTC June 24 as the AR made landfall on the Alaska Panhandle

84 (Fig. 1d). With a strong and stable anticyclone to its southeast, this AR remained quasi-stationary

85 in the northeast Pacific for more than 24 hours (Fig. 1e), and began to dissipate and disconnect

86 with the Asian monsoon system around 0000 UTC June 26 (Fig. 1f). It was able to transport

87 significant heat and moisture inland across the Pacific Coast Ranges that separate Alaska from

88 western Canada (Fig. 1e,f). Note that the highest mountain in Canada (and the second highest in

89 North America), Mount Logan, is located this region $\left(5959 \mathrm{~m}, 60.57^{\circ} \mathrm{N}, 140.41^{\circ} \mathrm{W}\right)$.

\section{Anomalous atmospheric patterns}

91 To reveal the atmospheric processes responsible for driving the oriental express across the North

92 Pacific (Fig. 1), we calculated the 5-day (June 21-25, 2021) mean anomalies of SLP, IWV, and

93 Z500 with respect to their 30-year (1991-2020) climatology. As shown in Fig. 2a, the North

94 Pacific High off the west coast of NA dominates the SLP distribution in the climatological map

95 (line contours) for this early summer period. Its western extension into the subtropical northwest

96 Pacific forms an important component of the East Asian summer monsoon ${ }^{25}$. Around this time,

97 the Aleutian Low has often reached its minimum intensity or virtually disappeared ${ }^{26}$. This was

98 not the case in 2021. In Fig. 2a, the lowest 5-day mean SLP anomaly is $-21.5 \mathrm{hPa}$ in the

99 extratropical North Pacific. It was mainly this anomalous extratropical cyclone in conjunction 
100

with the stable North Pacific High that created the strong horizontal pressure gradient needed to force the northeastward advance of the oriental express from the subtropical northwest Pacific.

The two bands of large positive IWV anomalies in Fig. $2 \mathrm{~b}$ indicate that the tropical export from the Asian summer monsoon was capable of contributing a large amount of moisture to the oriental express as it moved across the North Pacific basin. Some authors have argued that ARs may be considered as the footprints left behind on the cyclone pathway, and local sources are primarily responsible for the high water vapour content within the AR core ${ }^{27-29}$. The current understanding is that strong ARs are capable of pumping moisture out of tropical regions and incorporating midlatitude sources of water vapour along their paths ${ }^{30,31}$.

The anomaly pattern of Z500 in Fig. 2c reveals a well-defined train of Rossby waves propagating from the subtropical northwest Pacific into the extratropical Northern Hemisphere. It provides a physical explanation to the intensification of the Aleutian Low that drove the orient express across the North Pacific basin. Previous studies have shown that this wave train can be linked to phase 7 of the boreal summer intraseasonal oscillation in Southeast Asia ${ }^{14,15}$.

\section{Orographic precipitation and cross-mountain moisture transport}

Landfalling ARs are capable of producing heavy precipitation in mountainous areas, especially in the cold season with water vapour supplied by tropical moisture sources ${ }^{8,11,23,32-37}$. ARs in the warm season should produce less orographic precipitation because the warmer atmosphere can contain more water vapour before condensation begins than can a cooler atmosphere. The AR depicted in Fig. 1 was intercepted by the Pacific Coast Ranges when it made landfall over the Alaska Panhandle during June 24-26, 2021. This prolonged landfall did not produce extremely heavy precipitation. Figure 3a shows the 3-day total precipitation amounts from this event. The maximum amount was reported in the Alaska Panhandle area, and was only $121 \mathrm{~mm}$. Nevertheless, there were a few flooding events in late June 2021 that could be attributed to this 
124 AR, not because of heavy rainfall but from warm advection associated with the system leading to 125 a significant build-up of ice melt ${ }^{38,39}$.

126 Another explanation for the precipitation inefficiency of this AR is the spillover of moisture 127 and hydrometeors from the windward into the lee side of the mountains. We have seen in Fig. 1 128 that this AR penetrated deep into western Canada after its landfall. Figure $3 \mathrm{~b}$ presents a vertical 129 cross-section of the AR over the northeast Pacific valid at 0000 UTC June 25. It shows that, 130 although the AR core was located near $1000 \mathrm{~m} \mathrm{ASL}$, the air column between 2000 and $5000 \mathrm{~m}$ 131 contained a large amount of water vapour that was available for transport across the Pacific

132 Coast Ranges. Some condensates generated by the orographic uplift on the windward side within 133 this layer may also have been carried to the leeside where the descending airstreams would tend 134 to dissipate cloud and lessen any potential rainfall through re-evaporation. The leeward cloud 135 dissipation can be seen in the satellite imagery given in the SI (Fig. S4).

\section{The possible AR impact on the western North America heatwave}

137 The warm and moist air transported by the AR from the Pacific Ocean into western Canada 138 was trapped under a ridge of high pressure in the upper troposphere (see Fig. S2 in the SI). These

139 processes could be essential for the heat dome development, i.e., the build-up of an exceptionally 140 hot air mass when high pressure aloft prevented warm air below from rising and the subsidence 141 associated with the high pressure caused further warming by compression ${ }^{40}$. This heat dome was 142 responsible for the extreme heatwave in western North America from late June through mid-July $1432021^{15,41}$.

144 Figure 4 shows the anomalies of 5-day mean IWV and temperatures in North America 145 during June 26-30, 2021, together with their local correlation coefficients based on 43-year 146 (1979-2021) data from the ERA5 reanalysis. The positive IWV anomalies (Fig. 4a) in western 
147 Canada can be attributed jointly to the AR-induced moisture transport from the North Pacific

148 Ocean and the local evaporation/evapotranspiration under the heat dome. A narrow band with

149 even larger positive IWV anomalies across central and eastern NA was caused by a strong AR

150 formed in the Gulf of Mexico during this period; here the moisture was not locally trapped and

151 the AR produced some heavy precipitation events as it moved across the continent.

152 The anomalies of 5-day mean near-surface temperature $\left(\mathrm{T}_{2 \mathrm{~m}}\right)$ and lower-tropospheric mean

153 temperature ( $\bar{T}$, see Methods for definition) are shown in Fig. 4b. The intensity and extent of the

154 heatwave are indicated by the significant positive temperature anomalies in western NA. As

155 shown in the SI (Fig. S4), the extreme heatwave started in Washington State and spread rapidly

156 southward into Oregon and northward across BC and Alberta in western Canada. It generated

157 some of the highest temperatures ever recorded in this region, including the new Canadian record 158 of $49.6^{\circ} \mathrm{C}$ measured at Lytton, BC on June $29,2021^{41}$.

159 The correlation maps in Fig. 4c,d show that across Canada the air temperatures are

160 positively correlated with the local IWVs during June 26-30. In many regions, including northern

$161 \mathrm{BC}$ on the leeside of the Pacific Coast Ranges, the correlation coefficients are higher than 0.80.

162 Although correlation does not necessarily imply causation, it is reasonable to assume that the

163 moisture injected by the AR into western Canada had a positive feedback loop to amplify the

164 heatwave development in late June 2021. It is well known that water vapour is the dominant

165 greenhouse gas that traps infrared radiation in the atmosphere ${ }^{16-19}$. Therefore, the moisture

166 trapped under the heat dome is able to cause further warming of the lower troposphere. This

167 argument can be justified by noting that the build-up of IWV anomalies in late June 2021 was

168 slightly ahead of the rapid temperature increases over western Canada, as evident from a detailed

169 comparison between Figures S5 and S6 in the SI. On the other hand, one could also argue that 
170 the IWV build-up in western Canada was coincidental, because the advection in of moisture

171 from the AR happened because of the building upper ridge that provided the trajectory for the

172 moisture. In addition, it is possible to have more water vapour in an air parcel at a higher

173 temperature than at a lower temperature, because the saturation vapour pressure is uniquely

174 determined by temperature (with little pressure dependence).

175 An indirect support for our above argument of positive feedback loop comes from our

176 verification of the operational predictions of this AR event. Figure 5 shows the IVT distributions

177 valid at 0000 UTC June 25, 2021 as analysed and predicted by the Global Deterministic

178 Prediction System (GDPS) ${ }^{42}$ of Environment and Climate Change Canada. The analysed AR

179 over the northeast Pacific (Fig. 5a) was well predicted by the NWP model with lead times (LT)

180 up to 96 hours (Fig. 5b,c). The predictions with LT = 144 and 192 hours (Fig. 5d,e) could still be

181 considered as good guidance for the arrival time and landfall location of the AR. However, the

182 deep inland-penetration of the AR into western Canada was not correctly predicted by these

183 model runs, which were initialized at 0000 UTC June 19 and 17, respectively. The model run

184 initialized 10 days ahead (Fig. 5f) gave a poor prediction of landfall location of the AR at 0000

185 UTC June 25.

186 Figure 6 shows the analysed and predicted $\mathrm{T}_{2 \mathrm{~m}}$ valid at 0000 UTC June 27 . We see that the 187 temperature pattern in western Canada was well predicted with LT $=144 \mathrm{~h}$, i.e. from the NWP 188 model initialized at 0000 UTC June 21 (Fig. 6a vs Fig. 6b). It is shown in Fig. 5 that the inland189 penetration of the AR at 0000 UTC June 25 was also correctly predicted by the model run 190 initialized as early as June 21. The model initialized at 0000 UTC June 19 or 17 provided poor 191 guidance for both the AR penetration (Fig. 5d,e) and the temperature distribution (Fig. 6c,d) in 192 western Canada. 


\section{Concluding remarks}

194 We have described an anomalous warm-season AR moving across the North Pacific Ocean

195 in late June 2021 and dubbed it the oriental express. This system brought tropical moisture to the

196 west coast of NA from the summer monsoon system in Southeast Asia. It was driven by an

197 anomalous atmospheric pattern, which may have been forced by the boreal summer intraseasonal

198 oscillation in Southeast Asia ${ }^{14,15}$. The landfall of this AR over the Alaska Panhandle injected a

199 large amount of moisture into western Canada. Some of this water vapour accumulated under a

200 ridge of high pressure and may have formed a positive feedback loop to enhance the heatwave

201 development over western NA during late June and early July 2021. A rapid attribution analysis

202 has pointed out that that the occurrence of this extreme heatwave is virtually impossible without

203 human-caused climate change ${ }^{41}$. Our results provide evidence that moisture must be considered

204 when assessing heatwave development in a changing climate. Because ARs are narrow corridors

205 of strong horizontal water vapour transport concentrated in the lower atmosphere, their landfall

206 not only has the potential to produce heavy orographic precipitation, but is also possible to

207 contribute to the development of an inland heat dome in summer.

208 Although one of the main issues in this study is assessing whether the moisture advected

209 into western Canada via the AR has a significant effect on the heatwave, our analysis is not able

210 to quantify this impact to an order of magnitude. Some questions remain to be addressed, such as

211 1) How much of the anomalous water vapour was transported in, and how much was contributed

212 locally through evaporation and evapotranspiration? 2) What is the timescale over which adding

213 water vapour to the atmosphere leads to enhanced temperatures locally at the surface? Probably

214 these issues can be addressed in a more quantitative manner by running a model with and 
215 without the water vapour feed into western Canada and analysing what differences arise in the

216 heatwaves produced by the model. This approach is beyond the scope of this article.

\section{Methods}

218 Atmospheric river identification methods. The vertically integrated vapour transport (IVT)

219 and integrated water vapour (IWV) are two commonly used variables in AR analysis. They can

220 be defined as ${ }^{1,3,23}$

221

$$
\mathrm{IVT}=\sqrt{Q_{u}^{2}+Q_{v}^{2}}, \quad \mathrm{IWV}=g^{-1} \int_{p_{\mathrm{t}}}^{p_{\mathrm{b}}} q \mathrm{~d} p
$$

222 where

$$
Q_{u}=g^{-1} \int_{p_{\mathrm{t}}}^{p_{\mathrm{b}}} u q \mathrm{~d} p, \quad Q_{v}=g^{-1} \int_{p_{\mathrm{t}}}^{p_{\mathrm{b}}} v q \mathrm{~d} p
$$

224 In the above equations, $g$ is the acceleration due to gravity $\left(g=9.81 \mathrm{~m} \mathrm{~s}^{-2}\right), q$ is the specific

225 humidity, $u$ and $v$ are the zonal and meridional velocities, respectively, and $p$ is the air

226 pressure. The vertical integration is from the top $\left(p=p_{\mathrm{t}}\right)$ to the bottom $\left(p=p_{\mathrm{b}}\right)$ of the

227 atmosphere. $Q_{u}$ and $Q_{v}$ represent the zonal and meridional components of the integrated water 228 vapour flux, respectively.

229 There have been many AR identification and tracking algorithms in the literature based 230 mainly on the distribution of IVT, IWV, or a combination of the two ${ }^{43}$. In this study we choose a

231 simple method called the $\mathrm{IVT}_{250} \mathrm{scheme}^{44}$, which defines an $\mathrm{AR}$ as a contiguous region $\geq 2000$

$232 \mathrm{~km}$ in length with IVT $\geq 250 \mathrm{~kg} \mathrm{~m}^{-1} \mathrm{~s}^{-1}$. For warm-season ARs, one may also increase the 233 criterion to $500 \mathrm{~kg} \mathrm{~m}^{-1} \mathrm{~s}^{-1}$ to get an $\mathrm{IVT}_{500}$ scheme. 
235 Data sources. The main data sources for this study are the ERA5 global reanalysis ${ }^{24}$ and the

236 operational numerical weather prediction (NWP) output from the Global Deterministic

237 Prediction System (GDPS) of Environment and Climate Change Canada ${ }^{42}$. The ERA5 has hourly 238 output on a $0.25^{\circ} \times 0.25^{\circ}$ latitude-longitude grid; we only use the 0000 and $1200 \mathrm{UTC}$ data in

239 June from 1979 to 2021. The GDPS uses a Yin-Yang grid with an approximate horizontal

240 spacing of $15 \mathrm{~km}$. It provides weather forecasts up to 10 days, and is run twice daily initialized at 2410000 and 1200 UTC, respectively. Both the ERA5 output and the GDPS analysis are considered 242 as observations.

243 The daily precipitation data used to produce Fig. 3a are from the Climate Prediction Center 244 (CPC) Global Unified Gauge-Based Analysis ${ }^{45}$ provided by the NOAA/OAR/ESRL PSL,

245 Boulder, Colorado, USA, from their web site at

246 https://psl.noaa.gov/data/gridde d/data.cpc.globalprecip.html. The land-based data are available

247 on a $0.5^{\circ} \times 0.5^{\circ}$ latitude-longitude grid.

249 500-hPa geopotential height and mean temperature in the lowe $r$ troposphe re.

250 Meteorologists prefer to express the horizontal pressure gradient force in the mid-troposphere as

251 the gradient of geopotential along the $500-\mathrm{hPa}$ pressure surface. This level is, on average, around $2525.5 \mathrm{~km}$ above sea level. It is also common to consider mean temperature in the lower troposphere 253 as a function of the geopotential thickness between this level and the 1000-hPa level. This mean 254 temperature $(\bar{T})$ can be defined as

255

$$
\bar{T}=\frac{g(\mathrm{Z} 500-\mathrm{Z} 100)}{R \ln (2)},
$$

256 where $R$ is the gas constant for dry air $\left(R=287 \mathrm{~J} \mathrm{~kg}^{-1} \mathrm{~K}^{-1}\right), Z_{500}$ and $Z_{1000}$ are the geopotential

257 heights at the levels of 500 and $1000 \mathrm{hPa}$, respectively. 


\section{Acknowledgements}

260 We would like to thank Curtis Mooney for his internal review. RM is grateful to Judy Kwan,

261 Giselle Bramwell, Mark Barton, Cindy Yu, Mindy Brugman, Anthony Liu, and Amin Erfani for

262 helpful discussions on the extreme heatwave event.

263

264

\section{Competing interests}

265 The authors declare no competing interests.

\section{References}

2681 Newell, R. E., Newell, N. E., Zhu, Y. \& Scott, C. Tropospheric rivers?-A pilot study. Geophys. Res. Lett. 19, 2401-2404, doi:10.1029/92GL02916 (1992).

2 Zhu, Y. \& Newell, R. E. Atmospheric rivers and bombs. Geophys. Res. Lett. 21, 1999-

2002, doi:10.1029/94GL01710 (1994).

273

3 Zhu, Y. \& Newell, R. E. A proposed algorithm for moisture fluxes from atmospheric rivers. Mon. Wea. Rev. 126, 725-735, doi:10.1175/15200493(1998)126<0725:APAFMF>2.0.CO;2 (1998).

4 Browning, K. A. Radar measurements of air motion near fronts. Weather 26, 320-340, doi:10.1002/j. 1477-8696.1971.tb04211.x (1971).

5 Harrold, T. W. Mechanisms influencing the distribution of precipitation within baroclinic disturbances. Q. J. R. Meteorol. Soc. 99, 232-251, doi:10.1002/qj.49709942003 (1973).

6 Carlson, T. N. Airflow through midlatitude cyclones and the comma cloud pattern. Mon.

$280 \quad$ Wea. Rev. 108, 1498-1509, doi:10.1175/1520-0493(1980)108<1498:ATMCAT >2.0.CO;2 $281 \quad$ (1980).

2827 Rossby, C.-G. \& Collaborators. Isentropic analysis. Bull. Am. Meteorol. Soc. 18, 201-209, doi:10.1175/1520-0477-18.6-7.201 (1937).

8 Ralph, F. M., Neiman, P. J. \& Wick, G. A. Satellite and CALJET aircraft observations of atmospheric rivers over the eastern North Pacific Ocean during the winter of 1997/98. Mon. Wea. Rev. 132, 1721-1745, doi:10.1175/15200493(2004)132<1721:SACAOO>2.0.CO;2 (2004). http:/glossary.ametsoc.org/wiki/Atmospheric_river (2021). 
$29010 \quad$ Loukas, A. \& Quick, M. C. Spatial and temporal distribution of storm precipitation in southwestern British Columbia. J. Hydrol. 174, 37-56, doi:10.1016/0022-1694(95)027548 (1996).

11 Lackmann, G. M. \& Gyakum, J. R. Heavy cold-season precipitation in the northwestern United States: Synoptic climatology and an analysis of the flood of 17-18 January 1986. Wea. Forecasting 14, 687-700, doi:10.1175/15200434(1999)014<0687:HCSPIT>2.0.CO;2 (1999).

12 Dettinger, M. D. Fifty-two years of "Pineapple-Express" storms across the West Coast of North America. Report No. U.S. Geological Survey, Scripps Institution of Oceanography for the California Energy Commission, PIER Energy-Related Environmental Research. CEC-500-2005-004, 15 (2004).

13 Mo, R. Atmospheric rivers in the northeast Pacific: pineapple express. In Meteorology Today: An Introduction to Weather, Climate, and the Environment. 360-361 (C. D. Ahrens, P. L. Jackson, and C. E. O. Jackson, Nelson Education Ltd., 2016).

14 Lin, H. Monitoring and predicting the intraseasonal variability in the East Asian-western North Pacific monsoon region. Mon. Wea. Rev. 141,1124-1138, doi:10.1175/MWR-D12-00087.1 (2013).

15 Lin, H., Mo, R. \& Vitart, F. Can we predict the record-breaking 2021 western North American heatwave two weeks in advance? Geophys. Res. Lett., Submitted (2021).

16 Tyndall, J. On the absorption and radiation of heat by gases and vapours, and on the physical connexion of radiation, absorption, and conduction. London Edinburgh Dublin Philos. Mag. J. Sci. 22, 169-194, doi:10.1080/14786446108643138 (1861).

17 Tyndall, J. On radiation through the Earth's atmosphere. London Edinburgh Dublin Philos. Mag. J. Sci. 25, 200-206, doi:10.1080/14786446308643443 (1863).

18 Held, I. M. \& Soden, B. J. Water vapor feedback and global warming. Annu. Rev. Energy Env. 25, 441-475, doi:10.1146/annurev.energy.25.1.441 (2000).

19 Jacob, D. The role of water vapour in the atmosphere. A short overview from a climate modeller's point of view. Phys. Chem. Earth A26, 523-527, doi:10.1016/S14641895(01)00094- 1 (2001).

20 Bengtsson, L. The global atmospheric water cycle. Environmental Research Letters 5 , 025202, doi:10.1088/1748-9326/5/2/025002 (2010).

21 Lavers, D. A., Villarini, G., Allan, R. P., Wood, E. F. \& Wade, A. J. The detection of atmospheric rivers in atmospheric reanalyses and their links to British winter floods and the large - scale climatic circulation. Journal of Geophysical Research: Atmospheres 117, D20106, doi:10.1029/2012JD018027 (2012).

22 Guan, B.\& Waliser, D. E. Tracking atmospheric rivers globally: Spatial distributions and temporal evolution of life cycle characteristics. J. Geophys. Res. Atmos. 124, 1252312552, doi:10.1029/2019JD031205 (2019).

23 Mo, R. et al. Column relative humidity and primary condensation rate as two useful supplements to atmospheric river analysis. Water Resour. Res. 57, e2021WR029678, doi:10.1029/2021WR029678 (2021).

24 Hersbach, H. et al. The ERA5 global reanalysis. Q. J. R. Meteorol. Soc. 146, 1999-2049, doi:10.1002/qj.3803 (2020).

25 Ding, Y.Monsoons over China. 419 (Kluwer Academic Publishers, 1994).

26 Hordon, R. M. \& Binkley, M. in Encyclopedia of World Climatology (ed John E. Oliver) 35-36 (Springer Netherlands, 2005). 
27 Bao, J.-W., Michelson, S. A., Neiman, P. J., Ralph, F. M. \& Wilczak, J. M. Interpretation of enhanced integrated water vapor bands associated with extratropical cyclones: Their formation and connection to tropical moisture. Mon. Wea. Rev. 134, 1063-1080, doi:10.1175/MWR3123.1 (2006).

28 Cordeira, J. M., Ralph, F. M. \& Moore, B. J. The development and evolution of two atmospheric rivers in proximity to western North Pacific tropical cyclones in October 2010. Mon. Wea. Rev. 141,4234-4255, doi:10.1175/MWR-D-13-00019.1 (2013).

29 Dacre, H. F., Clark, P. A., Martinez-Alvarado, O., Stringer, M. A. \& Lavers, D. A. How do atmospheric rivers form? Bull. Am. Meteorol. Soc. 96, 1243-1255, doi:10.1175/BAMS-D-14-00031.1 (2015).

30 Dettinger, M., Ralph, F. M. \& Lavers, D. A. Setting the stage for a global science of atmospheric rivers. Eos 96, doi:10.1029/2015EO038675 (2015).

31 Eiras-Barca, J., Dominguez, F., Hu, H., Garaboa-Paz, D. \& Miguez-Macho, G. Evaluation of the moisture sources in two extreme landfalling atmospheric river events using an Eulerian WRF tracers tool. Earth Sys. Dyn. 8, 1247-1261, doi:10.5194/esd-81247-2017 (2017).

32 Ralph, F. M. et al. Flooding on California's Russian River: Role of atmospheric rivers. Geophys. Res. Lett. 33, L13801, doi:10.1029/2006GL026689 (2006).

33 Neiman, P. J., Ralph, F. M., Wick, G. A., Lundquist, J. D. \& Dettinger, M. D. Meteorological characteristics and overland precipitation impacts of atmospheric rivers affecting the West Coast of North America based on eight years of SSM/I satellite observations. J. Hydrometeorol. 9, 22-47, doi:10.1175/2007JHM855.1 (2008).

34 Lavers, D. A. et al. Winter floods in Britain are connected to atmospheric rivers. Geophys. Res. Lett. 38, L23803, doi:10.1029/2011GL049783 (2011).

35 Geng, Q. et al. Interaction of an intense Pacific low pressure system with a strong arctic outbreak over British Columbia: Forecast challenges of the early December 2007 storm. Atmos.-Ocean 50,95-108, doi:10.1080/07055900.2012.656261 (2012).

36 Mo, R. et al. Impacts of hydrometeor drift on orographic precipitation: Two case studies of landfalling atmospheric rivers in British Columbia, Canada. Wea. Forecasting 34, 1211-1237, doi:10.1175/WAF-D-18-0176.1 (2019).

37 Mo, R. \& Lin, H. Tropical-mid-latitude interactions: Case study of an inland-penetrating atmospheric river during a major winter storm over North America. Atmos.-Ocean 57, 208-232, doi:10.1080/07055900.2019.1617673 (2019).

38 Miller, M. Major flooding underway on Taku River near Juneau. Alaska Public Media, https:/www.alaskapublic.org/2021/2006/2030/major-flooding-underway-on-taku-rivernear-juneau/ (2021).

39 Windeyer, C. Flood warning issued for Yukon's Southern Lakes region. CBC News, https:/www.cbc.ca/news/canada/north/flood-warning-southern-lakes-yukon-1.6084551 (2021).

40 American Meteorological Society. Heat dome. Glossary of Meteorology, https://glossary.ametsoc.org/wiki/Heat_dome (2021).

41 Philip, S. Y. et al. Rapid attribution analysis of the extraordinary heatwave on the Pacific Coast of the US and Canada June 2021. Earth Sys. Dyn. Discuss., in review, doi:10.5194/esd-2021-90 (2021). 
38042 McTaggart-Cowan, R. et al. Modernization of atmospheric physics parameterization in Canadian NWP. J. Adv. Model. Earth Sys. 11, 3593-3635, doi: 10.1029/2019MS001781 (2019).

38343 Shields, C. A. et al. Atmospheric River Tracking Method Intercomparison Project (ARTMIP): project goals and experimental design. Geosci. Model Dev. 11,2455-2474, doi:10.5194/gmd-1 1-2455-2018 (2018).

38644 Rutz, J. J., Steenburgh, W. J. \& Ralph, F. M. Climatological characteristics of atmospheric rivers and their inland penetration over the western United States. Mon. Wea. Rev. 142,905-921, doi:10.1175/MWR-D-13-00168.1 (2014). Chen, M. et al. Assessing objective techniques for gauge-based analyses of global daily precipitation. J. Geophys. Res. Atmos. 113, D04110, doi:10.1029/2007JD009132 (2008). 
(a) 0000 UTC June 21, 2021

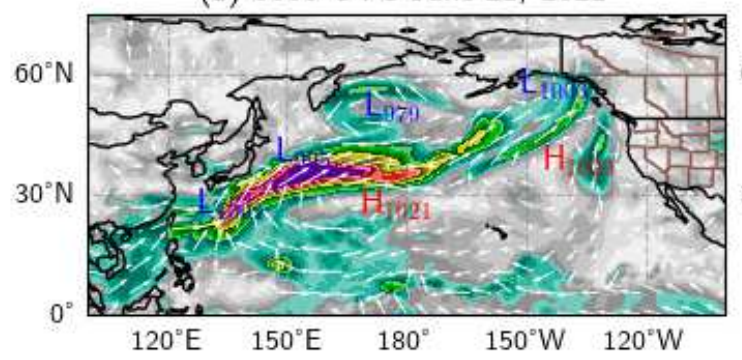

(c) 0000 UTC June 23, 2021

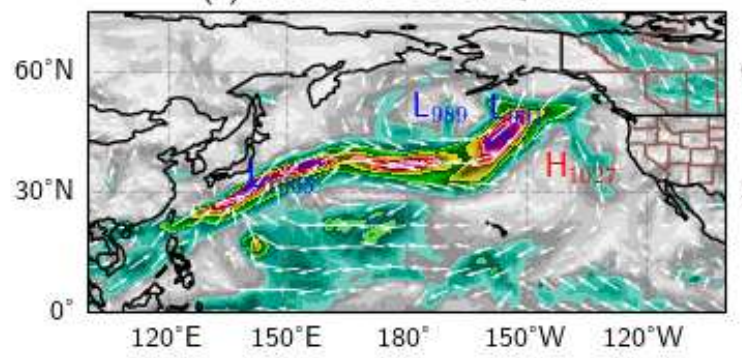

(e) 0000 UTC June 25, 2021

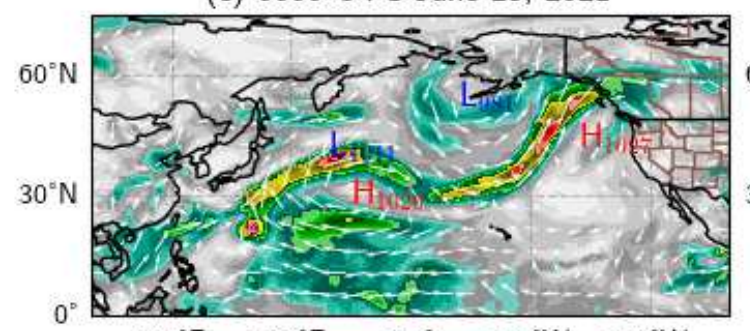

$\begin{array}{lllll}120^{\circ} \mathrm{E} & 150^{\circ} \mathrm{E} & 180^{\circ} & 150^{\circ} \mathrm{W} & 120^{\circ} \mathrm{W}\end{array}$ (b) 0000 UTC June 22, 2021

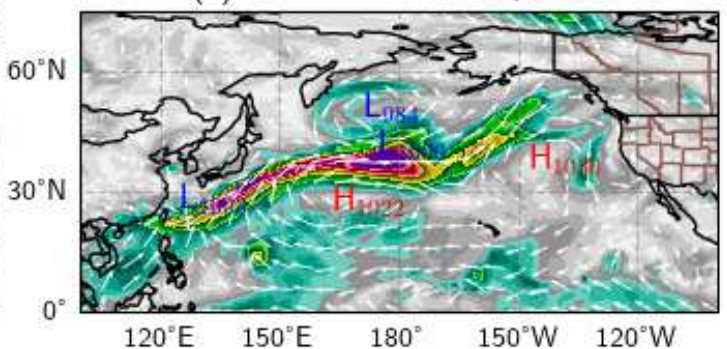

(d) 0000 UTC June 24, 2021

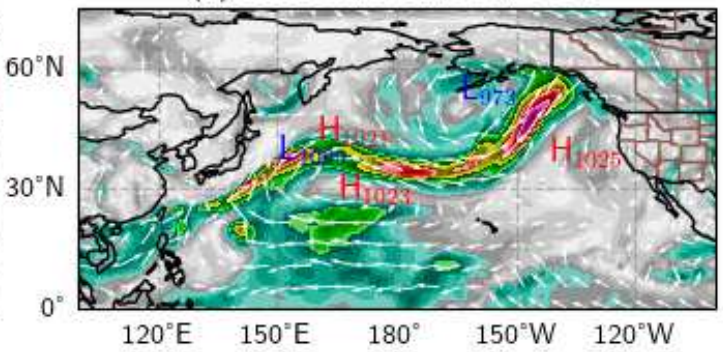

(f) 0000 UTC June 26, 2021

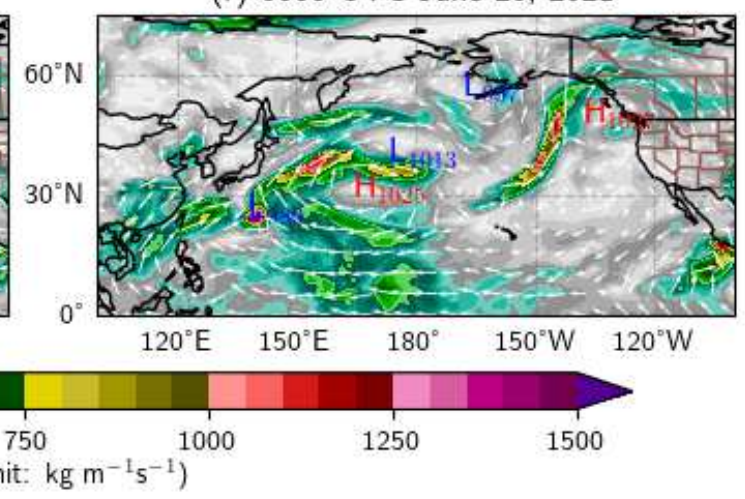

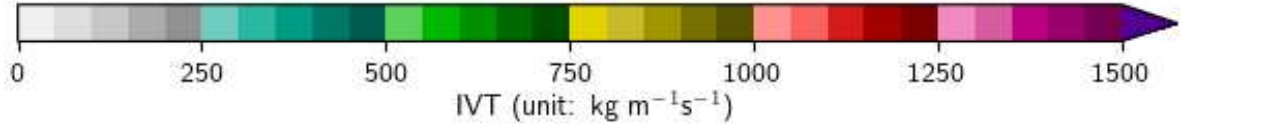

394 Fig. 1 | The IVT distributions valid at 0000 UTC J une 21-26,2021. Data are from the ERA5

395 reanalysis. The vector represents the integrated water vapour flux $\left(Q_{u}, Q_{v}\right)$ defined in Methods.

$396 \operatorname{IVT}=\left(Q_{u}^{2}+Q_{v}^{2}\right)^{1 / 2}$. The major high and low centres of SLP in the Pacific Ocean are marked by

397 letters "H" and "L" with their local maximum/minimum SLP values (in $\mathrm{hPa}$ ). 
(a) Sea level pressure $(\mathrm{hPa})$

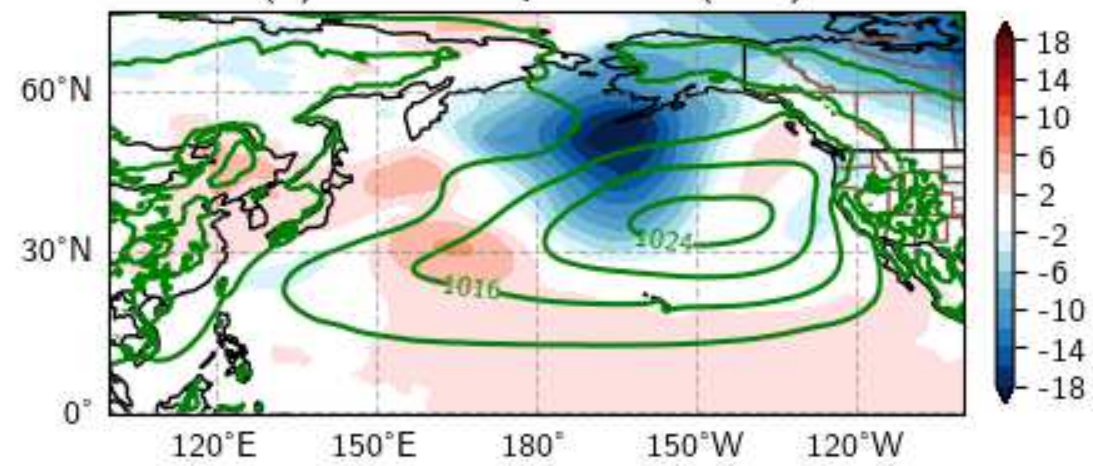

(b) Integrated water vapour $\left(\mathrm{kg} \mathrm{m}^{-2}\right)$

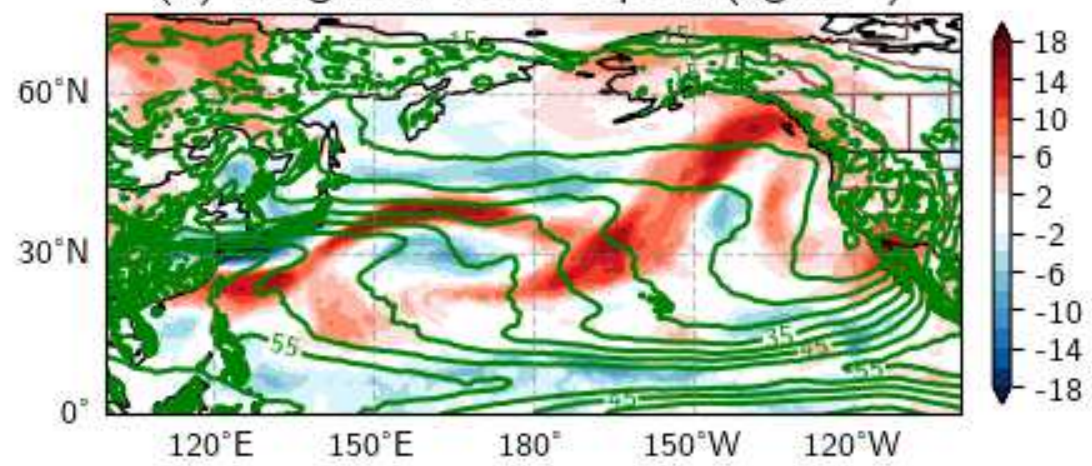

(c) $500-\mathrm{hPa}$ geopotential height $(\mathrm{m})$

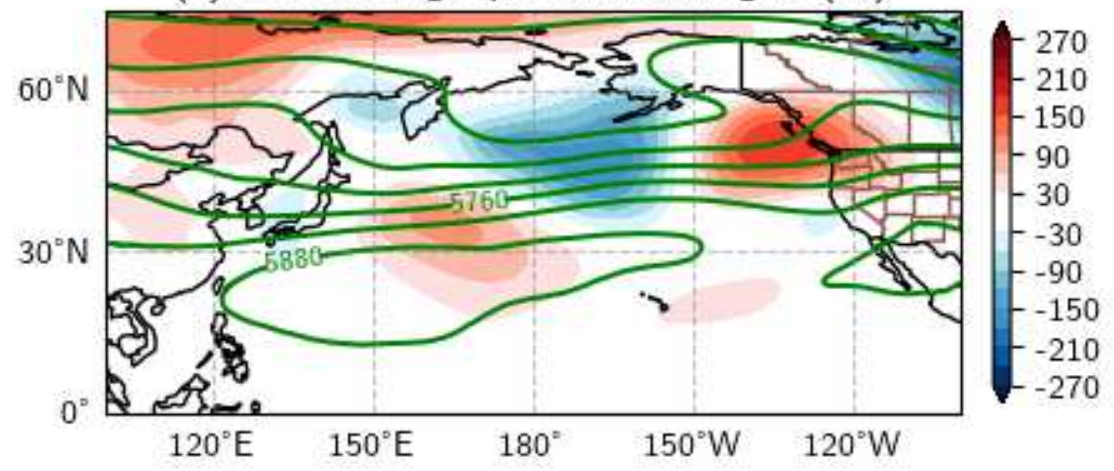

400 Fig. 2 | The anomalies of 5-day (June 21-25, 2021) me an SLP, IWV, and 500-hPa

401 geopotential he ight (colour contours) with respect to the ir 30-ye ar (June 21-25, 1991-2020)

402 climatology (line contours). The intervals of line contours are $4 \mathrm{hPa}$ in (a), $5 \mathrm{~kg} \mathrm{~m}^{-2}$ in (b), and

$40360 \mathrm{~m}$ in (c), respectively. All data are from the ERA5 reanalysis. 
(a) 3-day precipitation amount

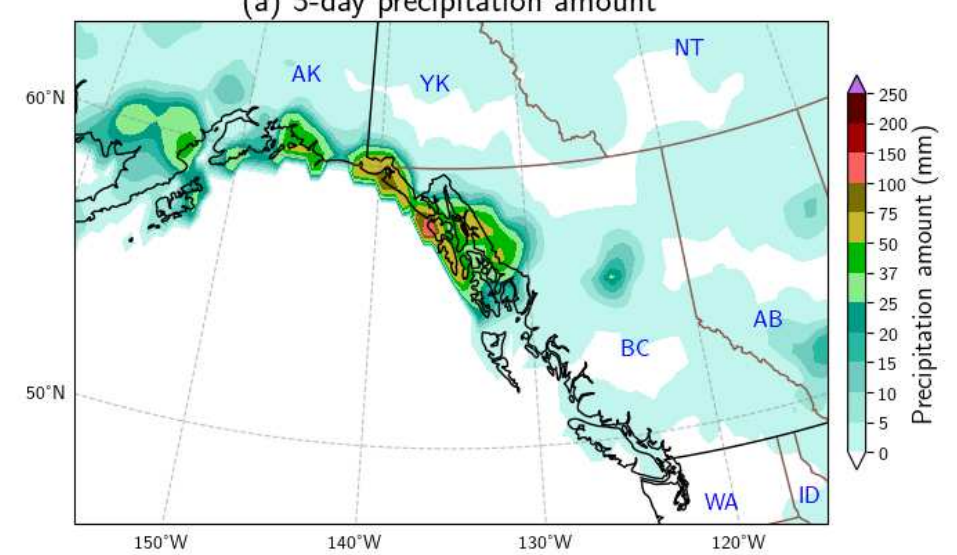

(b) Vertical cross-section diagram

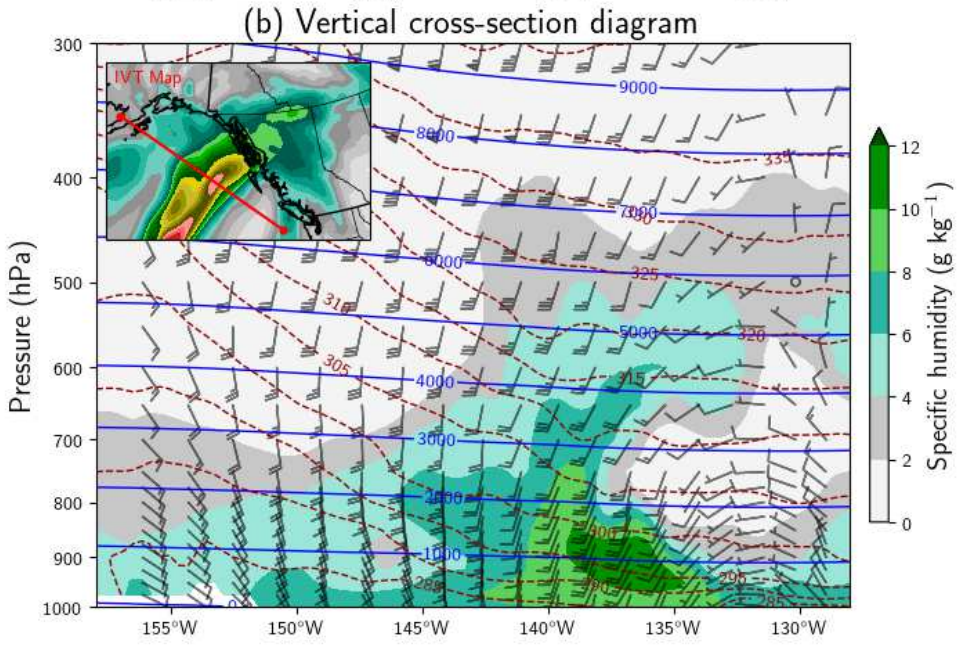

406 Fig. 3 | (a) The distribution of 3-day precipitation amount during June 24-26, 2021. The

407 daily precipitation data are obtained from the CPC Global Unified Gauge-Based Analysis (see

408 Methods for description). The 72-hour period ends at 0600 UTC in Canada and at 1200 UTC

409 June 26 in the United States. (b) A northwest-s outheast vertical cross section valid at 0000

410 UTC June 25, 2021 based on the ERA5 reanalysis. The cross-section location is indicated by a

411 red line in the embedded box. Colour-filled contours represent the specific humidity. Red dashed

412 lines are potential temperature contours (intervals: 5K). Blue solid lines are elevations ASL

413 (intervals: $1000 \mathrm{~m}$ ). Winds are indicated by the conventional wind barbs. 

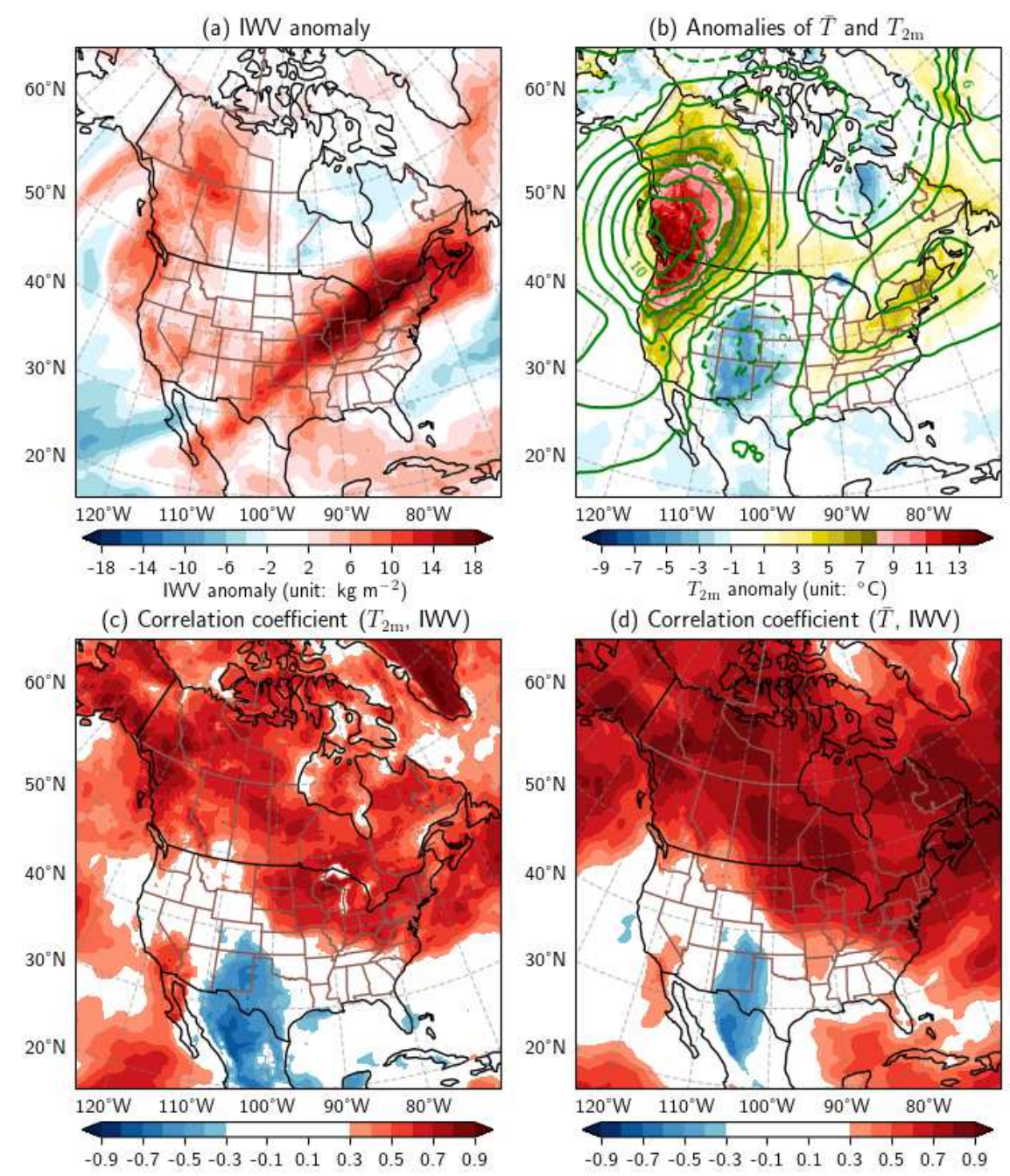

Fig. 4 | The anomalies of 5-day (June 26-30, 2021) mean IVW and air te mpe ratures,

417 toge the $r$ with the corre lation coefficients between them. All data are from the ERA5

418 reanalysis. The anomalies are calculated based on the 30-year (June 26-30, 1991-2020)

419 climatology. In (a), the IWV anomalies over western Canada can be attributed to the water

420 vapour transport from the oriental express. In (b), the lower-tropospheric averaged temperature (

$421 \bar{T}$ ) anomalies are represented by line contours with intervals of $2^{\circ} \mathrm{C}$, and the 2 -metre

422 temperature $\left(T_{2 \mathrm{~m}}\right)$ anomalies are colour-filled. In (c) and (d), the correlation coefficients are

423 calculated from 43-year (1979-2021) data; the coefficient values between -0.30 and 0.30 are

424 statistically insignificant with p-values beyond 0.05 based on the two-tailed Student t-test. 
(a) Analysis at 0000 UTC June 25 (LT =0)

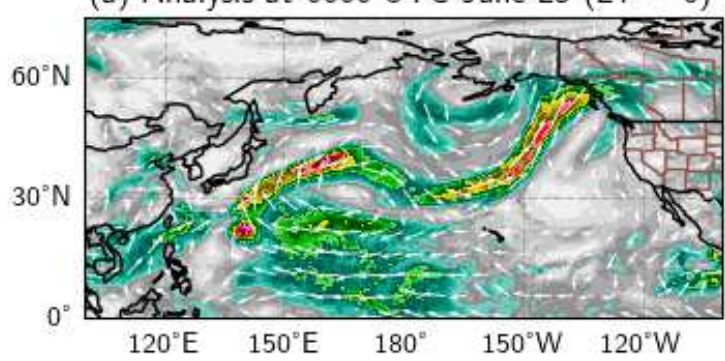

(c) Forecast from June $21(\mathrm{LT}=96 \mathrm{~h})$

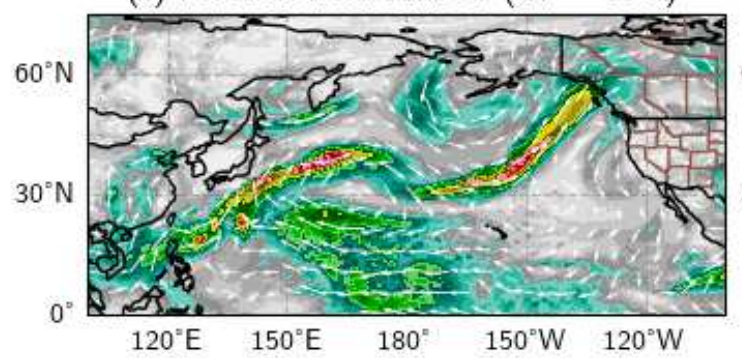

(e) Forecast from June $17(\mathrm{LT}=192 \mathrm{~h})$

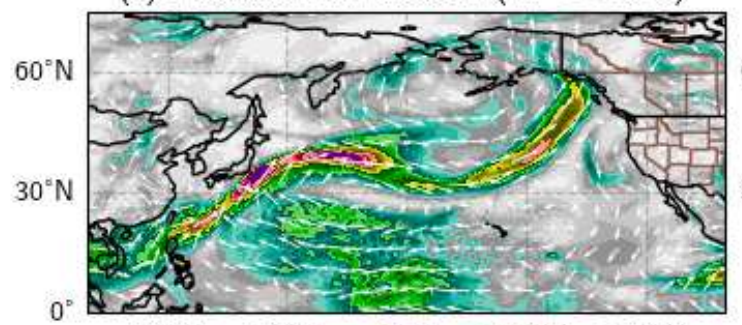

$\begin{array}{lllll}120^{\circ} \mathrm{E} & 150^{\circ} \mathrm{E} & 180^{\circ} & 150^{\circ} \mathrm{W} & 120^{\circ} \mathrm{W}\end{array}$ (b) Forecast from June $23(\mathrm{LT}=48 \mathrm{~h})$

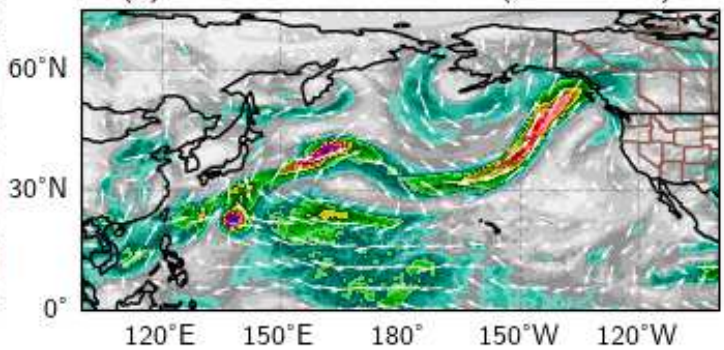

(d) Forecast from June $19(\mathrm{LT}=144 \mathrm{~h})$

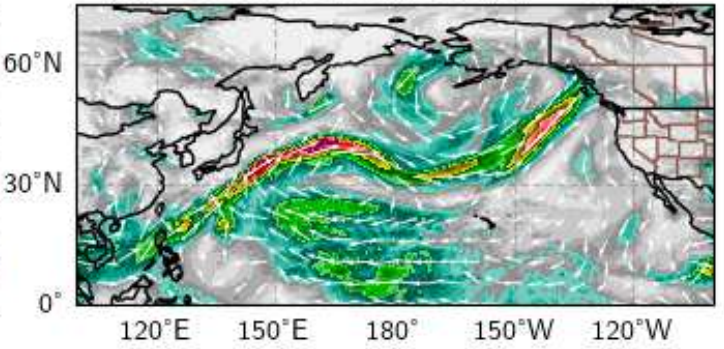

(f) Forecast from June 15 (LT $=240 \mathrm{~h}$ )

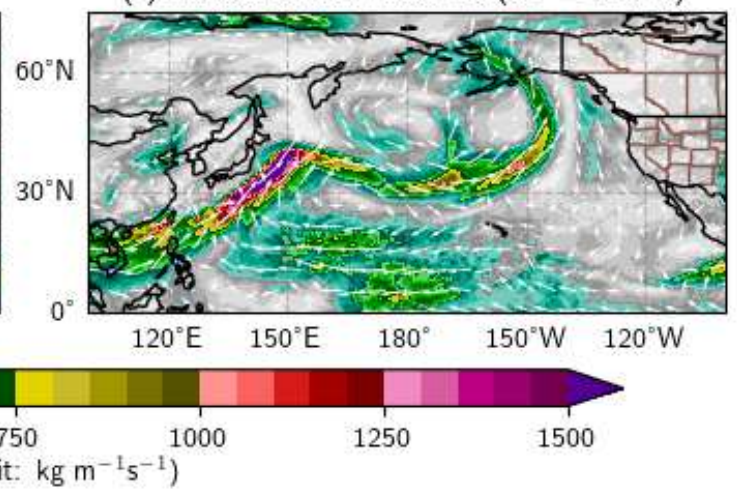

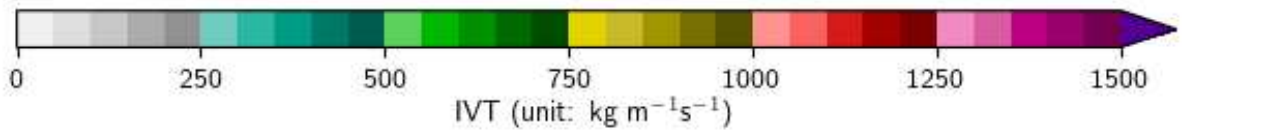

426 Fig. 5 | Distributions of the IVT valid at 0000 UTC 25 June 2021 bas ed on the Canadian

427 GDPS ope rational outputs. (a) The GDPS analysis. (b)-(f) The GDPS predictions with

428 different lead times (LT). 
(a) Analysis at 0000 UTC June $27(\mathrm{LT}=0)$

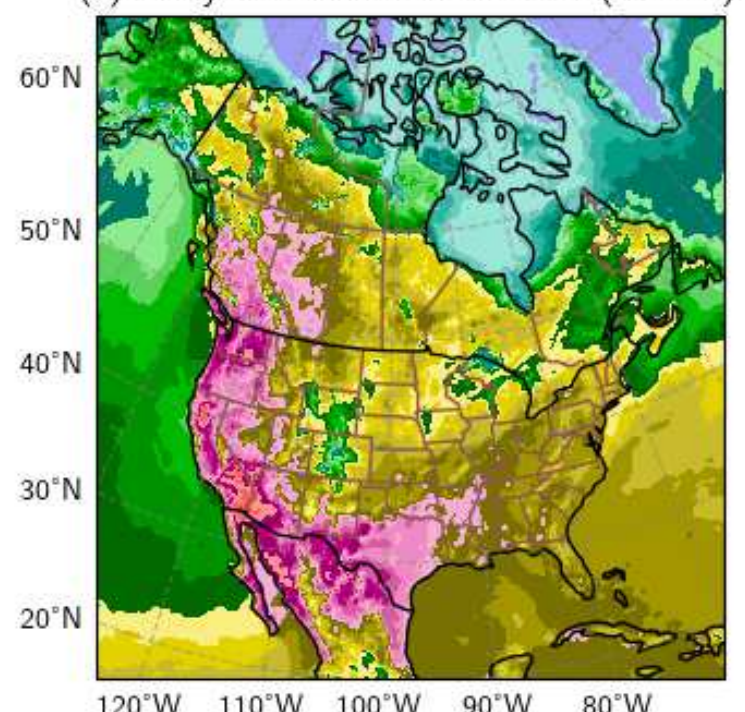

(c) Forecast from June $19(\mathrm{LT}=192 \mathrm{~h})$

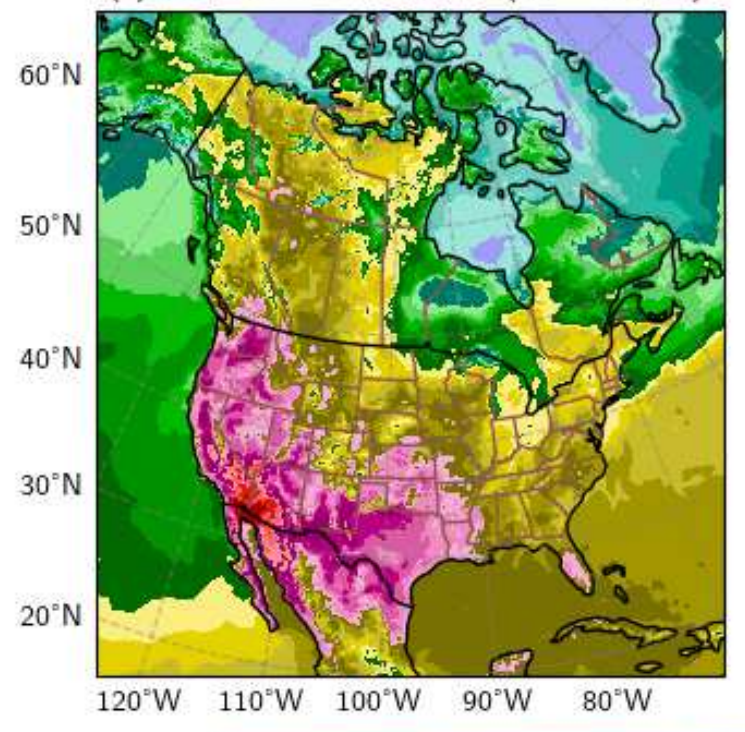

(b) Forecast from June $21(\mathrm{LT}=144 \mathrm{~h})$

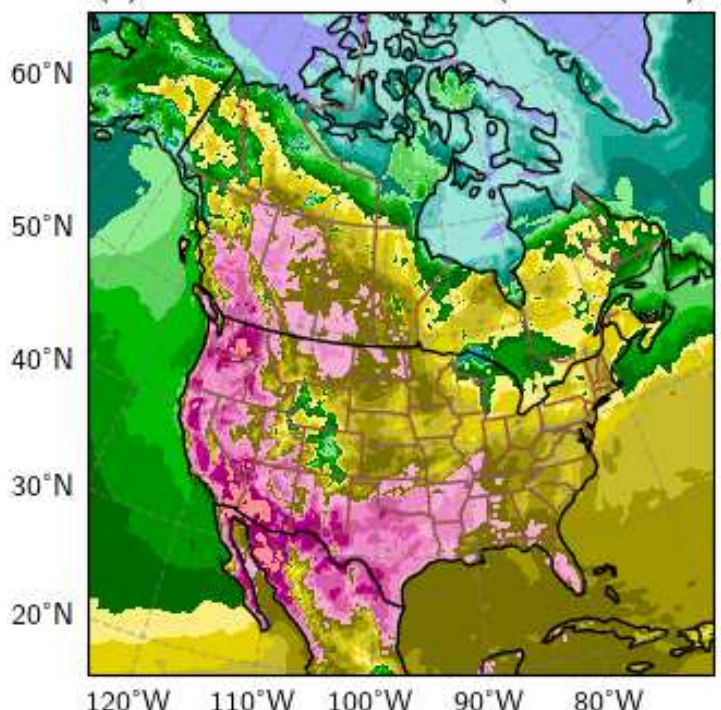

(d) Forecast from June $17(\mathrm{LT}=240 \mathrm{~h})$

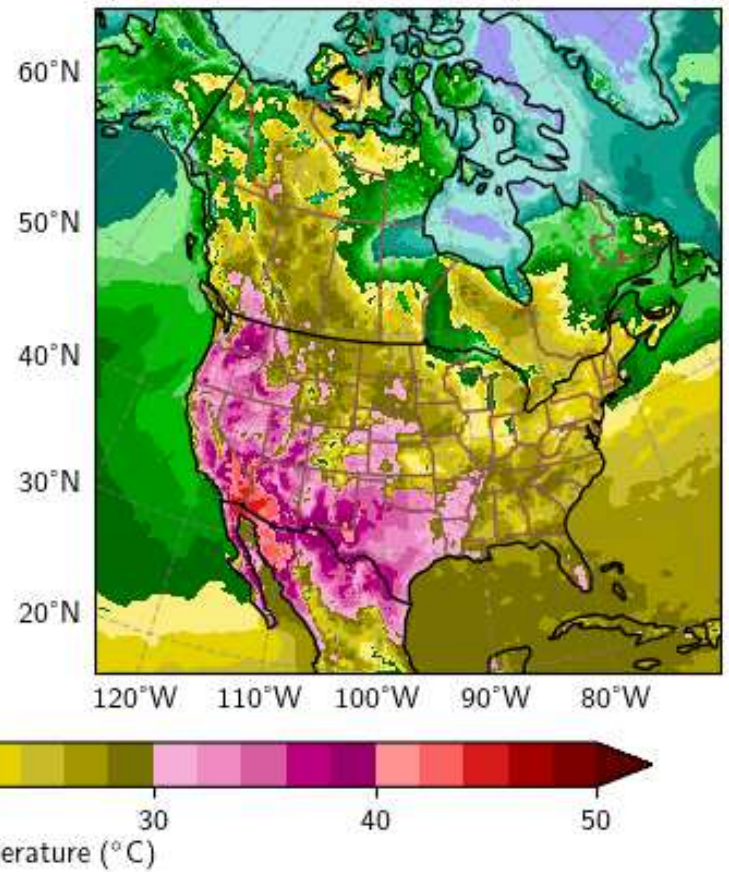

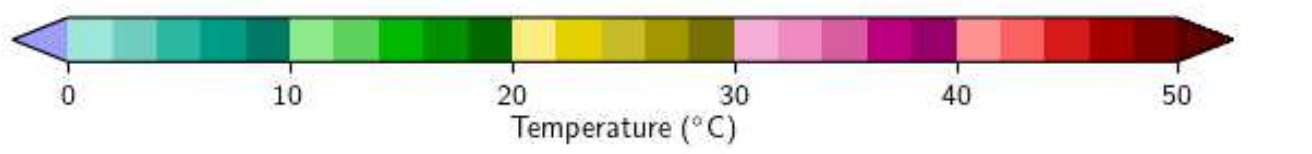

431 Fig. 6 | Distributions of the 2-metre temperature valid at 0000 UTC June 27, 2021 bas ed on

432 the Canadian GDPS ope rational outputs. (a) The GDPS analysis. (b)-(d) The GDPS

433 predictions with different lead times (LT). 


\section{Supplementary Files}

This is a list of supplementary files associated with this preprint. Click to download.

- SupplInfoAnomalousARlinkedtoNAheatwavesubmitted.pdf 